\title{
Income Inequality, Fertility, Human Capital Accumulation and Economic Growth in Mexico
}

\author{
Jorge Charles-Coll ${ }^{1}$, Elizabeth Mayer Granados ${ }^{1} \&$ María Isabel De la Garza Ramos $^{1}$ \\ ${ }^{1}$ Universidad Autonoma de Tamaulipas, Mexico \\ Correspondence: Prof. Dr. Jorge Charles-Coll, Universidad Autonoma de Tamaulipas, Mexico. E-mail: \\ jorgecharles@hotmail.com \\ Received: February 3, 2015 \\ Accepted: February 26, $2015 \quad$ Online Published: March 9, 2015 \\ doi:10.5430/rwe.v6n1p172 \\ URL: http://dx.doi.org/10.5430/rwe.v6n1p172
}

\begin{abstract}
This research analyses the relationship between the levels of inequality and the growth rate of the Mexican states using as theoretical reference the Inequality-Human capital theory proposed by De la Croix and Doepke (2003) which links negatively inequality to growth via its effects on the differentials in fertility rates and on human capital accumulation which affect the growth rate of a country on the long run. The findings are that the Mexican case fits exactly to the predictions. The poorest states are the ones with the higher fertility levels, the lower education levels and the ones in which the newborns mothers have the lower education level. It was also found that the richer states are the ones who absorb the effects of external economic shocks. The results infer that redistributive policies are not as important as providing equal and universal access to education in order to boost long term growth.
\end{abstract}

Keywords: income inequality, economic growth, redistribution, education, human capital

\section{Introduction}

It is widely acknowledged that the whole concept of development must be based on economic growth, understood as an increase in GDP, capital stock or any other indicator that measures the level of wealth in a country. However, economic growth does not necessarily imply development.

Wealth level indicators do not provide information about wealth distribution, or how much of it is used to provide for public health, education, social security, infrastructure, and employment. This is where the idea of development is linked to the concept of quality of life through distribution mechanisms. True development is only possible when these two ingredients are combined.

Nevertheless, among the intricate steps leading to economic development, there are factors such as inequality in income distribution that may impede this combination from occurring.

The objective of this article is to analyze the variables that connect the levels of inequality in Mexico with economic growth, using the "fertility-human capital" model by De la Croix \& Doepke (2003) as its theoretical framework. The model introduces a negative relationship between income inequality and rates of economic growth, derived from a cyclical effect that income level inflicts on both fertility rates and human capital accumulation.

According to this model, an individual with a low income will have many children and provide a lower level of education for them, while an individual with higher income will choose to have fewer children and provide them with better education. Thus, in economies with high degrees of inequality, where wealth is concentrated in a small percentage of the population, there will be a significant difference in fertility rates between high and low income groups, and the stock of human capital will decrease, causing negative effects on the country's economic growth rates.

The relation between inequality and economic growth in Mexico is an issue that, even though studied in the past as a socioeconomic problem (Lustig \& Szekely, 1997; Cortez, 2000; Ros \& Buillon, 2000, among others), it has never been analyzed under any economic theory that links the two variables with specific mechanisms.

The analysis of inequality as an economic phenomenon has been limited to the description of its effects in relation to poverty and as a basis to evaluate the economic and social policies applied by governments.

The document is divided into four parts. The first describes the theoretical framework in which this case study is based, as well as an overview of the different theories that developed to explain the relationship between inequality and economic growth. The second part encompasses the empirical elements, describing and analyzing the problem of 
inequality at a state level in Mexico, reviewing data on a variety of topics such as education, income, birth rates and economic growth. The third part describes the implications for economic policy. Finally, we include some concluding remarks.

\section{Theoretical Framework}

There has long been a debate over theories about the role of inequality in development. Isolating the variables, economic growth and inequality, becomes fundamental to establish their role in the various economic doctrines. A basic example is derived from the fundamental theorems of welfare economics, which illustrate the invisible hand advocated by Adam Smith, and the relation between economic efficiency and equality. The first axiom states that any equilibrium in competitive markets is Pareto-efficient, while the second states that under specific conditions, any Pareto-efficient distribution can be considered as a competitive equilibrium. It is understood that this result may or may not be equitable. Therefore, efficiency and equity in resource distribution are separable, thus they may not necessarily complement one another.

One of the most influential contributions of the twentieth century regarding the matter of inequality and its relationship to development was Simon Kuznets's hypothesis (Note 1) that a country, in its path to development, will most likely experience a period of high inequality and capital concentration. This is explained by the gradual movement by economic agents from the relatively less productive sector of agriculture towards the more productive industrial sector. (Kuznets, 1955)

The theory was proven about the same time by Kaldor (1956), who addressed the issue of causality and acknowledged the effect of income distribution on capital accumulation, and ultimately, on growth. This amounts to an overcoming of the Pareto optimal for redistribution, under the assumption that the benefits of such redistribution would notoriously compensate for the initial inequity.

Moreover, inequality also appears in the context of international trade theories. The Stopler-Samuelson theorem, in the context of the Heckscher-Ohlin international trade model, states that an increase in the relative price of a certain good will increase the real return to the factor intensively used in its production and will reduce the real return to the other factor. (Stopler \& Samuelson, 1941)

Addressed as the magnification effect, any change in the price of goods has a magnified effect on factor prices. The most important implication of this theorem is the existence of strong effects on income distribution that benefit some but negatively affect others. However, this does not conflict with the fact that as a rule there is a win-win formula in international trade.

While most of the debate during the twentieth century focused on the effects of growth on inequality levels, recent trends in development (Note 2), such as globalization and lack of convergence, opened a window for this topic to be addressed extensively, but from the effects of inequality on growth, the opposite causal perspective.

\section{The Relationship between Inequality and Growth}

Theoretical approaches to the relationship between income distribution and economic growth support both positive and negative linkages. The prospects vary, hence the importance of analyzing the empirical studies over the years to successfully identify the main schools of thought. The dominant position on this debate is that of the existence of a negative relationship between inequality and growth, supported by cross-sectional studies such as Ferreira (1999), Benabou (1996), Perotti (1996), De la Croix \& Doepke (2003), among others.

Nonetheless, there is an opposite current headed by Forbes (2000), who, based on longitudinal data analysis for developed countries, found a positive relationship between both variables that holds for both the short and the medium terms. Furthermore, Li and Zou (1998) obtained the same results using five year periods for their samples. Although both studies have a short-term perspective, they represent the main opposition to the widely accepted notion that inequality has negative effects on growth.

Persson \& Tabellini (1994) are among the leading advocates of the relationship between ex-ante inequality and economic growth. Using indicators for inequality such as education, physical capital investment or the relative income of the median voter, they present a political device for explaining this phenomenon by linking inequality with political inefficiency, which discourages private investment and, therefore, restrains economic growth.

Benerjee and Duflo (2000), through a cross-sectional study, found that absolute changes in levels of inequality (whether positive or negative) can diminish growth. In other words, any movement in the current state of distribution will produce negative effects on economic growth for the upcoming period of time. This is justified both by political economy arguments and by the effects of imperfect financial markets, which restrict access to credit. They found that, in the long run, there was an inverted U-shaped trend for this relationship; a result of a higher growth rate at intermediate levels of inequality. These levels tend to move towards intermediate values (Gini coefficient below 0.4) 
in the long run and, while this happens, growth rates tend to increase. However, when inequality descends further, growth rates will decrease (Laffer curve).

These long-term predictions are consistent with those of Barro (1999), who stated that, although the relationship between inequality, investment and growth is weak, there is a tendency which varies from country to country, specifically for different income levels, implying a nonlinear relation. By dividing the sample between rich and poor countries, Barro found that the trend is reversed in income levels of about \$2,000 dollars per capita GDP (1985 U.S. dollars). In other words, he found a long run inverted U-shape trend across income levels, meaning that inequality would be harmful for poor countries but good for richer ones, when it comes to economic growth.

Although these results are similar to those of Benerjee \& Duflo (2000) when compared to the Kuznets curve, one difference lies in the fact that the determinant of growth is not only the level of inequality, but in turn, inequality itself depends on income levels. Another disagreement lies in the explanation Barro (1999) offers for this nonlinear relationship. He argues that even when inequality in income distribution is high, as income levels increase, the negative effects of imperfect financial markets on the lower strata of the population diminish, while the advantages of the higher strata are preserved; as a consequence, growth rates improve. This does not mean that inequality becomes an incentive for growth after having reached a certain level of income. This increase in income neutralizes (or decreases) the negative effects that inequality has on financial markets, and consequently on investment and growth.

Alesina \& Perotti (1996) and Benabou (1996) arrived to similar conclusions, finding a correlation between inequality, political instability and growth. However, Benabou includes the role of imperfect credit markets as a disincentive to investment and growth in his model.

Finally, following the argument of a negative relationship between inequality and growth, De la Croix \& Doepke (2003) specify a model that links the long run effects of unequal income distribution with differential fertility rates for different economic strata.

These differentials would, in turn, reduce human capital, affecting long run economic performance. De la Croix \& Doepke (2003) state that this mechanism represents the most relevant consequence of inequality on growth, and they predict a Kuznets like behavior for inequality and fertility in the long run. In other words, inequality levels rise initially and then descends as the economy develops. This model is to be used in this article as a theoretical basis for analyzing the relationship between inequality and economic growth in Mexico.

The studies mentioned above represent the main results on the issue in recent years. To summarize, these studies suggest that the relationship between inequality and growth could be: (a) positive, (b) negative, or (c) negative in the short run while positive in the long run. (Figure 1)

As aforementioned, there are four mechanisms that represent the main currents of thought in this regard: the wealth effect mechanism, the economic policy mechanism, the socio-political instability mechanism and the fertility-human capital effect. This study focuses on the later.

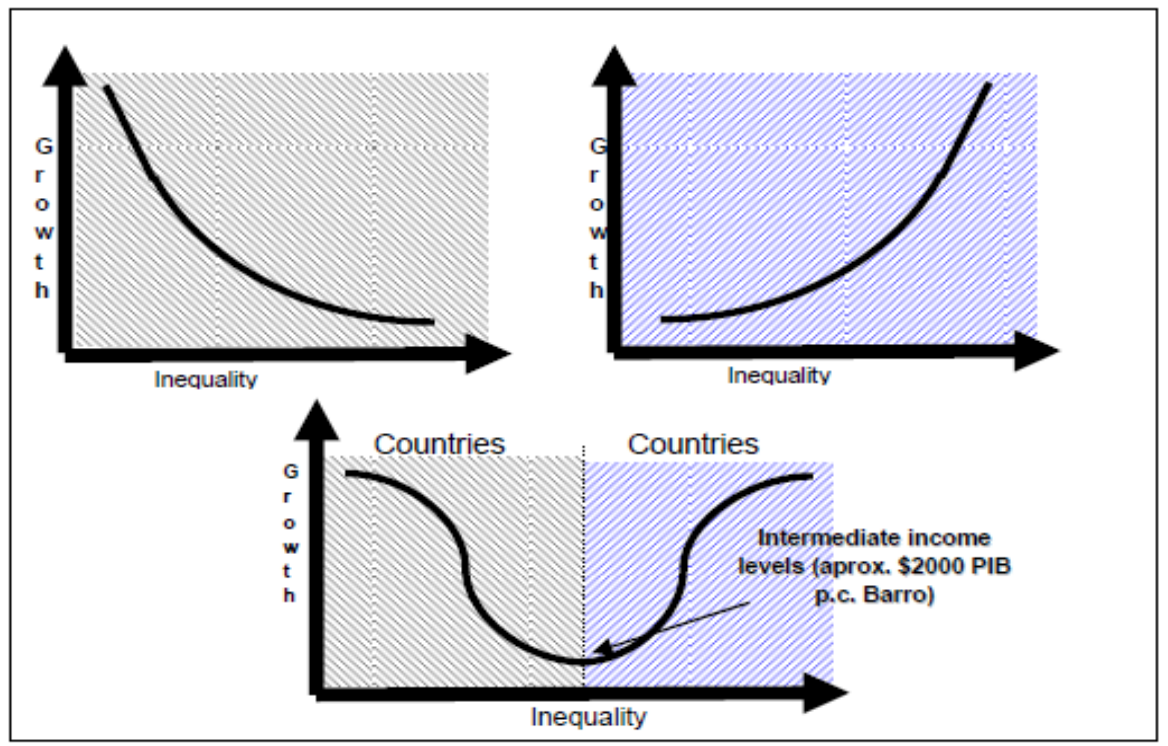

Figure 1. Negative, positive and non-linear relationship of inequality and growth 


\section{The "Fertility-Human Capital" Effect}

De la Croix \& Doepke (2003) develop a new theoretical link between inequality and economic growth by introducing an overlapping-generations model where fertility and education decisions are endogenous and interdependent. They argue that fertility differentials between the rich and the poor affect human capital accumulation and, in turn, economic growth.

The authors assume that, in deciding how many children to have, parents might face a dilemma between quantity and quality. Parents with higher income would prefer to have fewer children and may offer better education, while parents with lower income would have more children but may not be able to provide them much education.

The argument is that for the rich, the opportunity costs of having more children are higher than for the poor. As fertility decisions are endogenous, this creates a differential in birthrates that, paired with the effect of income levels on education quality, decreases the stock of human capital in the economy, and finally generates a negative effect on growth rates.

In a cross-sectional sample of 68 countries, they found that countries with highly unequal income distribution have higher fertility differentials, accumulate less human capital and have lower rates of economic growth. Furthermore, simulations showed that an increase in Gini coefficient from 0.2 to 0.65 reduces the initial growth rate at $1.4 \%$. This effect, calibrated for the US economy, is quantitatively important and accounts for most of the relationship between inequality and growth.

It is also worth mentioning that the nature of this mechanism implies that each period corresponds to one generation, so this model predicts effects on growth rates in the long run. In fact, the authors state that the model can explain the evolution of income, fertility and inequality in the last 200 years in industrialized countries.

One of the most relevant and controversial implications of this model is that the results do not necessarily suggest that the implementation of redistributive policies will generate economic growth since the differentials in income levels, despite their importance, are only a part of the mechanism. Within this framework, ensuring access to education to all economic strata would be a more effective policy.

Moreover, other studies arrive to similar conclusions. Ahituv \& Moav (2003) tested the existence of fertility clubs by use of an overlapping generation model in which they finally converge to one of two steady states; one of them (referred to as "low") is characterized as a poverty trap in which there is a high birth rate and low economic growth. The authors argue that this duality in steady states is derived from the effect of the level of parental education on the cost of children. They claim that education, and specifically female education, generates reductions in birth rates and increased growth rates. Likewise, the high fertility rates in poor countries or countries with inequality in poor strata reduces the growth rate through human capital.

Castello \& Domenech (2006) developed a model in which inequality affects per capita income when individuals decide to invest in education by taking into account their life expectancy, which depends largely on the human capital of the parents. Their results demonstrate the existence of multiple steady states which depend in turn on the initial distribution of education. This study is coincident with Ahituv \& Moav (2003) in asserting the existence of a "low" steady state which is a poverty trap in which children from poor families have low life expectancy and poor education. The authors claim that this mechanism explains most of the relationship between inequality and existing human capital stock. The arguments of the model can be summarized as follows:

- An increase in the levels of inequality generates differentials in fertility, decreases levels of average education, human capital and thus also growth levels.

- The mechanism explains the growth trends in the past 200 years in industrialized countries.

- Inequality causes the negative effect on growth rates, but the solution to this is not necessarily the implementation of redistributive policies.

- The effects of this mechanism are reflected only in the long term because each period comprises a generation.

The "fertility-human capital" mechanism is suited for this research on the Mexican economy as it is based on a sequence of logical arguments and results easy to contrast on the information available. Additionally, this mechanism counts on more theoretical support than others, since it is based in human capital and demographic transition theories.

Other theories that seek to explain the relationship between inequality and growth have some disadvantages that complicate empirical research, mainly due to rigid assumptions or the difficulty to measure the variables. An example of this is the policy mechanism, which operates only under the assumption of existence of a progressive tax system, and a uniform distribution of political power. These assumptions are difficult to meet, especially in unequal developing economies. Another example would be that of the mechanism of socio-political instability, which requires an indicator that is based on an instability index for which no information is available. 


\section{Inequality in Mexico}

It is widely acknowledged that income distribution in Mexico is highly unequal, especially regarding the gap between the richest $5 \%$ and the poorest $5 \%$. The most accurate indicator for measuring inequality in a country is the Gini coefficient, which measures the distance between the proportions of the population with different income levels.

In 2010, Mexico had a Gini coefficient of .47, comparable to Kenya or Uzbekistan, which are much less developed countries compared to Mexico. Structural differences in wealth distribution show that according to development indicators half of the population live in poverty and two thirds of the employees earn an income below three minimum wages, even though per capita GDP is 12,700 dollars. Considering that the average wage is distributed between 2.5 persons, we conclude that $66 \%$ of the population earns an income which is below 56.4 pesos a day, the equivalent of 1,800 U.S. dollars a year.

Table 1. Gini coefficient in México (1992-2012)

\begin{tabular}{cc}
\hline Year & Gini coeficient \\
\hline 1992 & 0.474 \\
1996 & 0.455 \\
2000 & 0.481 \\
2002 & 0.454 \\
2004 & 0.46 \\
2010 & 0.472 \\
2012 & 0.481 \\
\hline
\end{tabular}

Inequality is not homogeneously distributed throughout Mexican territory. There are significant levels of meso-inequality across regions which are frequently overlooked when working with an aggregate analysis as they are not evident in statistics.

A clear example of this is the information regarding the nominal per capita GDP (uncorrected for inflation and expressed in dollars) for the different states of the country. In the richest states, such as Nuevo León and Distrito Federal, nominal per capita GDP is around $\$ \$ 14,567$ for the first and $\$ 17,800$ for the latter; while in the poorest states like Chiapas, Oaxaca, Guerrero or Tlaxcala, average per capita GDP ranges between $\$ 3,452$ and $\$ 4,348$. Although data is statewide and does not reflect wealth inequality within each state, it does provide an account for the high degree of economic heterogeneity among regions in Mexico.

Map 1 presents interstate inequality levels for each range of labor income, measured in minimum wages, together with the distribution of labor across the territory; darker colors indicate higher levels of income inequality.
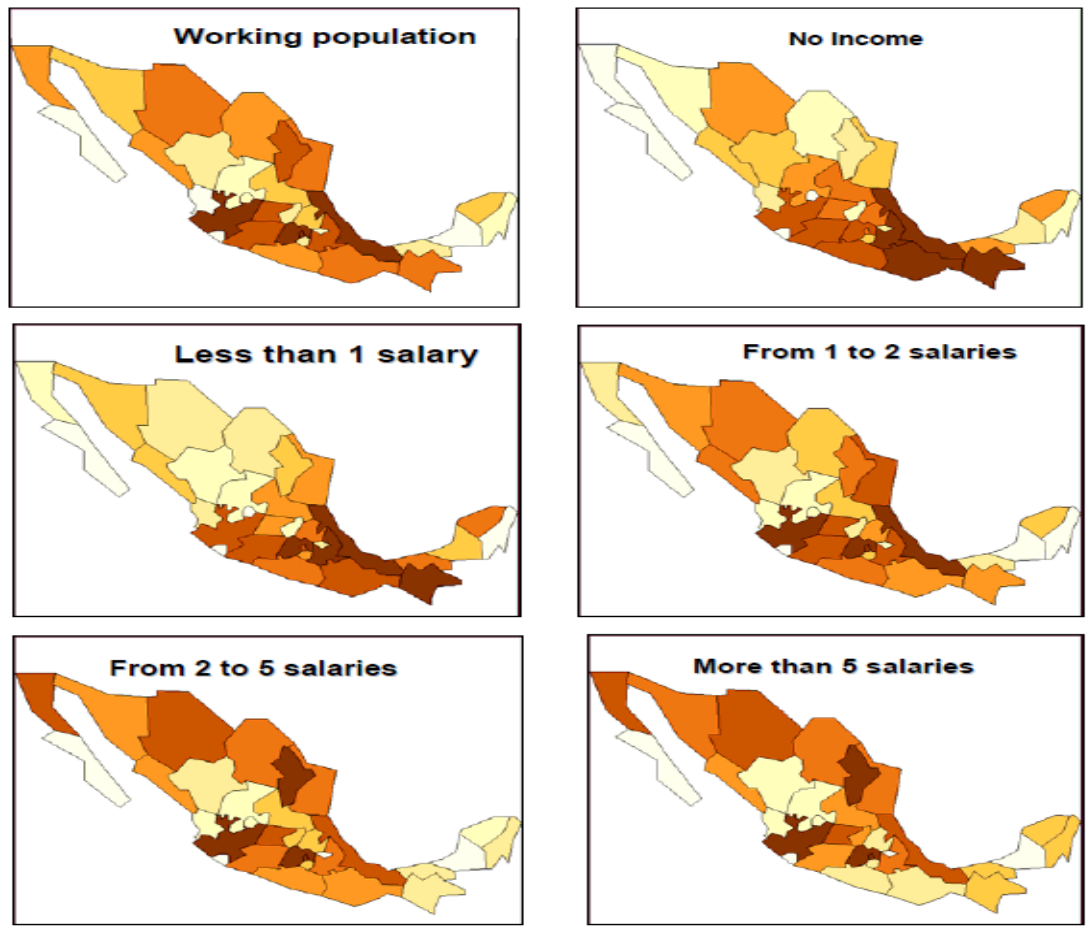

Map 1. Income distribution in Mexican states (2010) 
The next step in this research is to test the assumptions in De la Croix \& Doepke (2003) for the Mexican case and verify that the causal relationship between inequality and growth is consistent with predictions in this theory.

\section{Education}

Human capital is a concept that encompasses the attributes of a productive individual, mainly related to his/hers amount of knowledge or skills which in turn determines their productivity. Most modern studies in economic growth include human capital as a growth determinant. Mankiw, Romer \& Weil (1992), in one of the most influential articles in the field of growth theory, propose a Solow style model (with exogenous savings rates) augmented to include human capital.

Because of its close relationship with education, the idea of including human capital in a production function implies that the higher the education level of a country, the higher will be the rate of economic growth. However, the effect over the economy varies when considering different academic levels. We found that secondary education is strongly linked to economic growth rates, while primary and higher education have a greater effect on wealth distribution. From this we conclude that a policy that promotes access to university level education in Mexico will be beneficial not only for its impact on economic growth by means of increasing human capital accumulation, but also for its positive incidence on wealth distribution.

When analyzing inequality in access to higher education, we find, once more, evidence of a negative relationship between income levels and education, with Chiapas topping the list with the lowest average level of schooling (6.1 years), followed by Guerrero, Michoacan, Veracruz and Zacatecas, all of them with levels well below average ( 8.1 years) and significantly lower than those of Distrito Federal (10.1 years) and Nuevo León (9.4 years).

Regarding the degree of coverage of higher education, we observe that the poorest states are those with less coverage. While, on average, only $13.01 \%$ of the Mexican population has access to higher education, in states like Chiapas or Guerrero this figure decreases to $7.55 \%$ and $7.92 \%$ respectively, while among the richest states coverage rate raises up to $22.32 \%$ in the case of Distrito Federal, or $18.8 \%$ in Nuevo León.

Even though there have been great strides in recent years, the degree of coverage of higher education in Mexico is still deficient. Not even those states with the highest coverage levels reach countries such as Iceland, New Zealand and Sweden, which top the list of countries with the highest coverage at this level. In the OECD (Organization for Economic Cooperation and Development), Mexico has the second lowest coverage of tertiary education, just above Turkey and below the other twenty-four member countries.

It follows that policies of expansion of higher education coverage must focus both on reducing regional disparities in access to education, and to increase the national averages of coverage. Promoting nationwide convergence in coverage is a necessary but not sufficient step. Expanding enrollment is more important for achieving the human capital accumulation required for improving the competitiveness of the Mexican economy and stimulate economic growth.

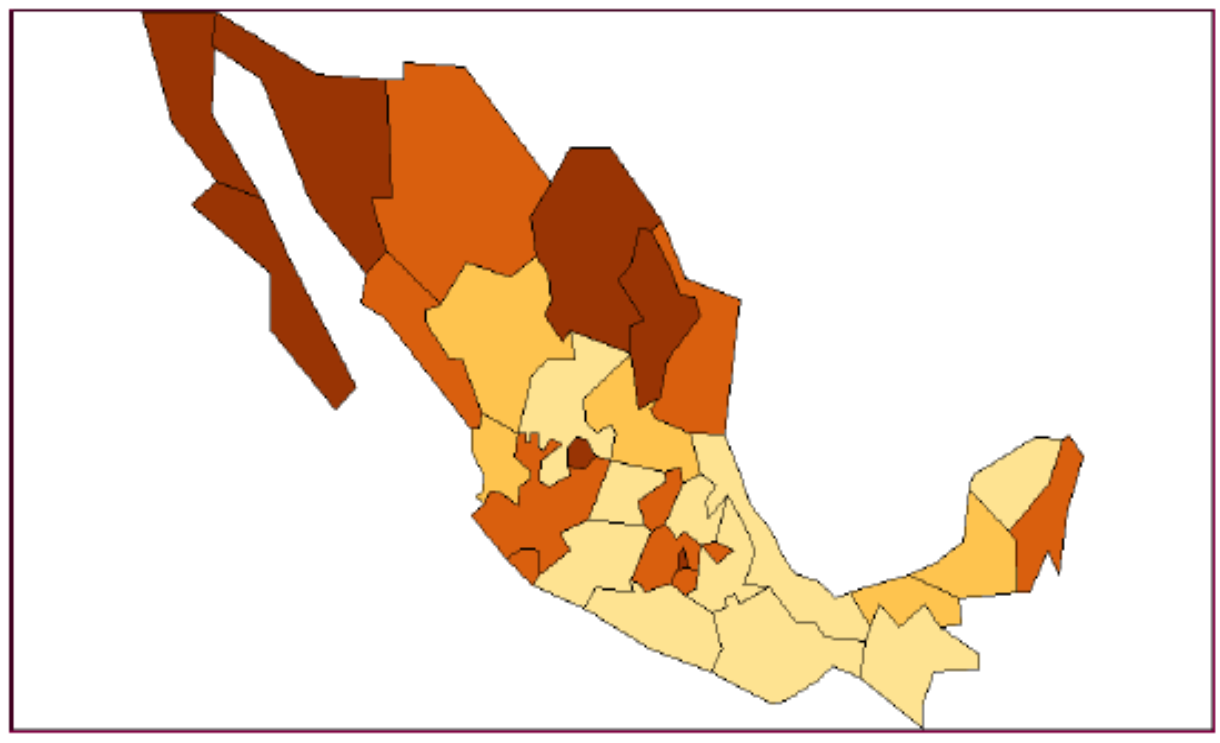

Map 2. Average years of schooling in Mexican states (pop. 15yrs and older) 2010

Source: INEGI 


\subsection{Indigenous People and Access to Education}

In Mexico, there is a strong correlation between poverty and the native status of a person. Currently, there are over 6.01 million natives spread across the country, about $6.7 \%$ of the total population. This minority is undoubtedly the most disadvantaged and the one that suffers the most from inequality. Coincidentally, the poorer states of Mexico are also those in which the percentage of indigenous population is higher. Chiapas and Oaxaca lead with $26.1 \%$ and $35.3 \%$, closely followed by states like Guerrero (14.2\%), Hidalgo (15.5\%) and Veracruz (9.5\%).

According to official data, natives in Mexico have an average of 4.5 years of schooling, about half the national average of 8.1 years. Regarding higher education, only $3.9 \%$ of the indigenous population has attended at least one year of higher education much less than the national average of $13.8 \%$.

\section{Fertility Rates}

As described above, the poorest states in terms of income are: Chiapas, Guerrero, Oaxaca, Veracruz and Zacatecas. Some of these states have a GDP six times lower than some of the wealthiest states in the country like Distrito Federal, Nuevo León or Jalisco.

When analyzing fertility rates, we see coincidence with the assumptions of the theory. The poorest states have the highest fertility rates, surpassing in some cases such as Chiapas in 13\% the national average and in $31 \%$ the state with the lowest birth rate (Note 3).

Furthermore, we found that the negative relationship between income levels and birth rates also applies to the richest states. Distrito Federal has the lowest fertility rates across the country with 15.8 per thousand. The trend is quite clear; with only a few exceptions, the vast majority of states have indicators that match the predictions of the theory. (Table 2)

Supposing that the assumption that individuals with less education will have lower income holds, we test the hypothesis of a positive relationship between poverty and fertility by comparing birth rates with educational indicators for Mexican states. Results show that the poorest states are also those with the highest birth rates and the highest proportion of births to mothers with no education or even high school education. For example, in Chiapas $75 \%$ of the newborn's mothers have no education or even high school, similar figures were found in states like Guerrero and Oaxaca, with $68.4 \%$ and $67 \%$ respectively.

Table 2. Total fertility rate in Mexican states (2010)

\begin{tabular}{lclclc}
\hline \multicolumn{1}{c}{ State } & TFR & \multicolumn{1}{c}{ State } & TFR & \multicolumn{1}{c}{ State } & TFR \\
\hline Aguascalientes & 19.4 & Guerrero & 19.8 & Quintana Roo & 19.6 \\
Baja California & 17.3 & Hidalgo & 18.2 & San Luis Potosí & 18.7 \\
Baja California Sur & 16.8 & Jalisco & 17.9 & Sinaloa & 16.7 \\
Campeche & 18 & México & 17.4 & Sonora & 17.1 \\
Coahuila & 17.5 & Michoacán & 18.3 & Tabasco & 18.4 \\
Colima & 16.7 & Morelos & 16.8 & Tamaulipas & 17.2 \\
Chiapas & 20.7 & Nayarit & 17.1 & Tlaxcala & 19.1 \\
Chihuahua & 17.2 & Nuevo León & 16.7 & Veracruz & 17.4 \\
Distrito Federal & 14.6 & Oaxaca & 18.7 & Yucatán & 17.3 \\
Durango & 18.3 Puebla & 19.4 Zacatecas & 18.4 \\
Guanajuato & 19.2 & Querétaro & 18.5 & & \\
\hline
\end{tabular}

On the other hand, this effect is confirmed in the wealthiest states, as the opposite results are found in states such as Distrito Federal or Nuevo León, where only $17 \%$ and $22.4 \%$ of newborns are children of mothers with no schooling or with only high school education, respectively. The following polygonal maps represent the state distribution of birth rates (Map 3), and birth rates according to mother's education level (Map 4). Darker colors indicate higher birth rates (and vice versa). 


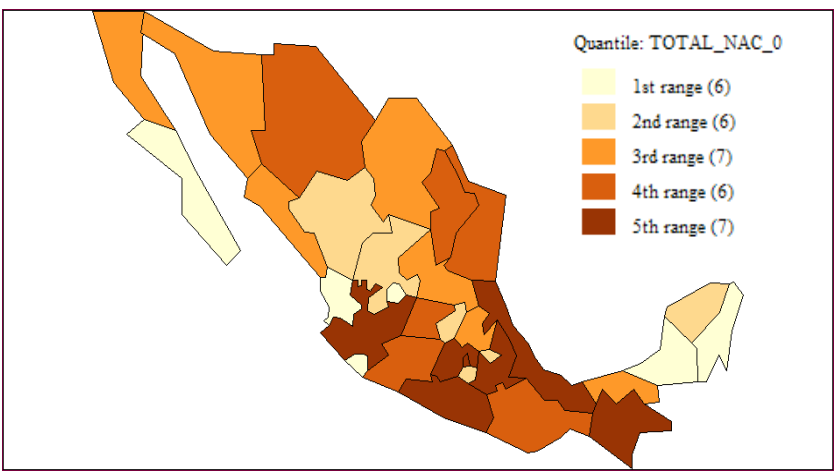

Map 3. Fertility rates in Mexican states (2010)
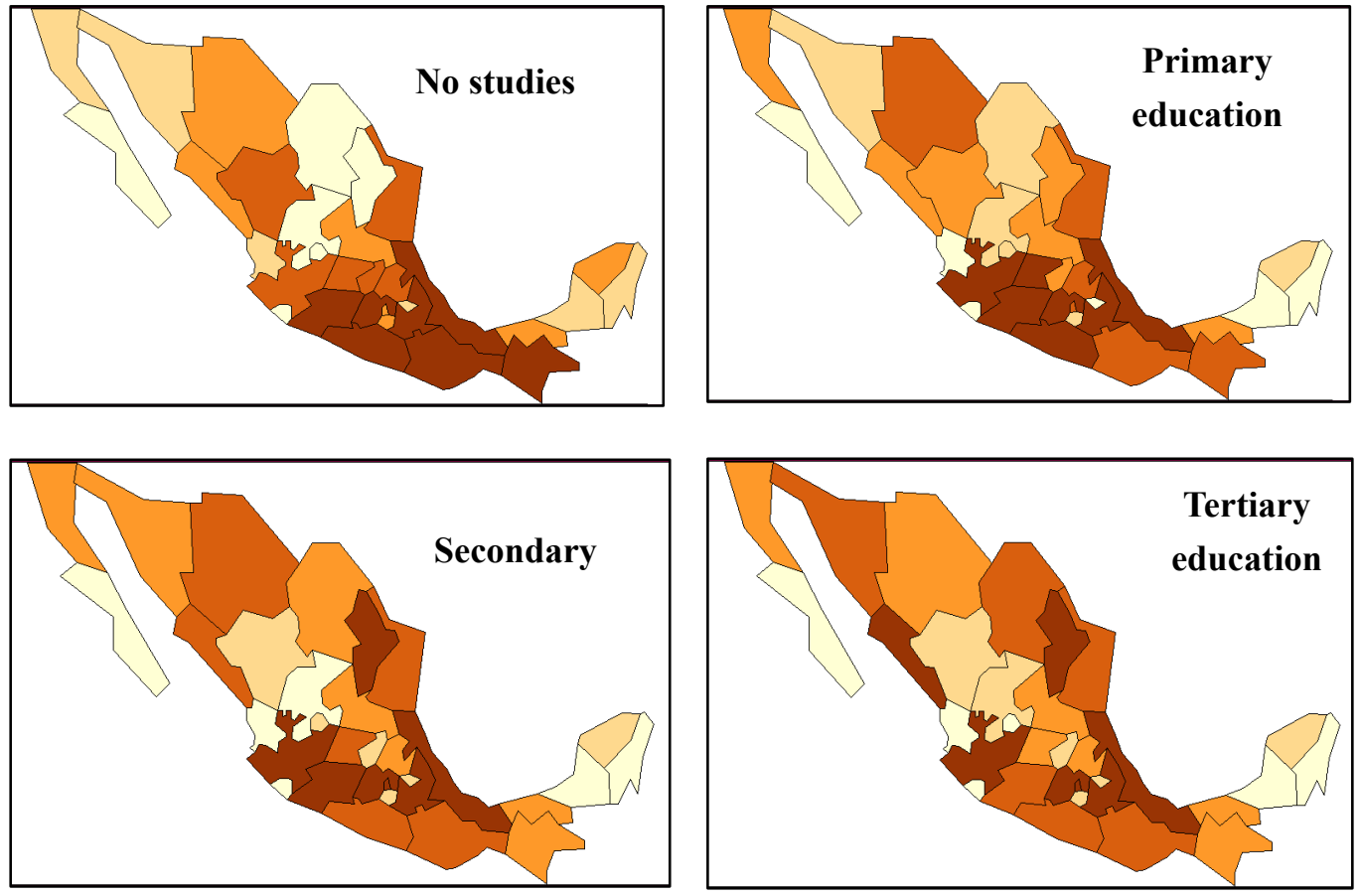

Map 4. Fertility rates in Mexican states according to education level (2010)

Finally, the scatter plots below show that the predictions of the theory are fulfilled in Mexico's case. Figure 1 demonstrates the existence of a strong positive relation between births to mothers with no schooling and national birth rates. Moreover, Figure 2 supports these results, confirming the thesis that a higher education level will cause fertility rates to decrease.

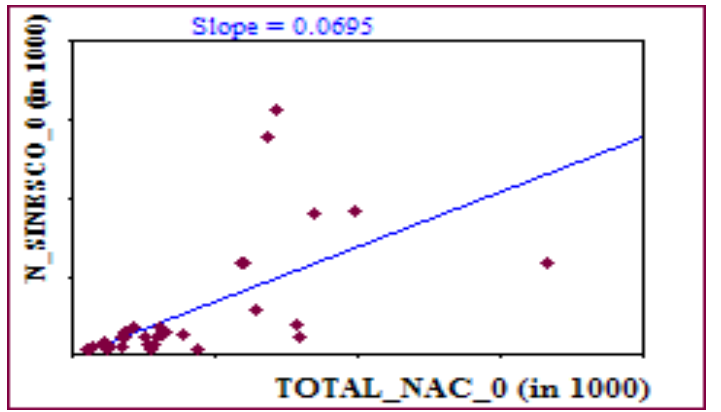

Figure 1. Relationship between births from mothers with no education and total fertility rates (2010)

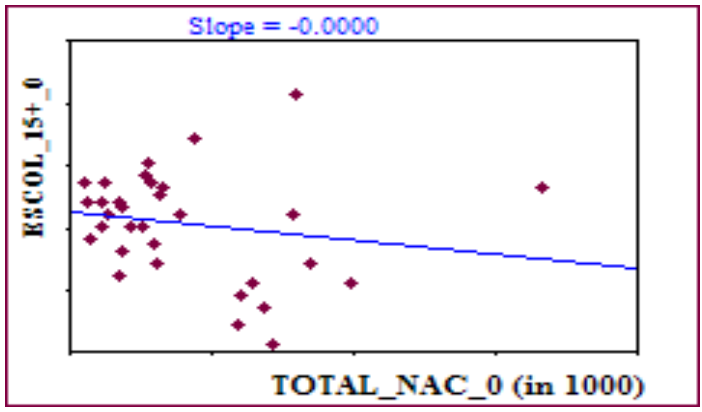

Figure 2. Relationship between school attainment and total fertility rates (2010) 


\section{Economic Growth}

In order to understand trends in economic growth, we must consider the geographic configuration of the Mexican economy, as productive structures differ substantially among states.

The signing of the North American Free Trade Agreement (NAFTA) with the United States and Canada in 1994 was the beginning of an unprecedented era of increased exports in the history of Mexico. After the 1995 crisis, levels of FDI increased dramatically, and manufacturing concentrated more than ever in the border states. Currently, the NAFTA zone is the region with the highest volume of international trade in the world, and Mexican foreign trade operations more than double those of all Latin American countries combined.

The Mexican economy became linked to the United States, since the neighbor country is the destination for more than $79 \%$ of its exports. Economic cycles in both countries are also tied and mostly follow the same trends and meet similar obstacles. The consequences of US recessions are, in many occasions, much graver for the Mexican economy, including immediate effects over exchange rates and trade balance, along with rising unemployment in the border states due to lower flows of US investment.

When analyzing data on GDP growth rates trends by state, we see a striking disagreement with the theory. Growth rates for the poorer and most unequal states must be below average while for the relatively wealthier states this indicator should be higher than average. In Table 3 we see that for the period comprised between 2003 and 2013, the most disadvantaged states had growth rates similar to the national figure, however, by further analyzing the information, we can find the reason for this contradiction.

As mentioned above, there are differences among the economic structures of the various states. Those states with lower income levels concentrate their economic activities in sectors with lower value added (such as agriculture or mining) and their target market is the domestic economy. On the other hand, those states with higher income levels receive the largest share of foreign direct investment and specialize in export-oriented activities (such as manufacturing, automotive industry, or services). Exporting states are therefore more vulnerable to external shocks generated by trade partners, especially, the United States. Furthermore, for this dataset, we find evidence that shows how the rich and exporting states were the most affected by the 2008-2011 crisis and specifically the recession that occurred in 2009. This difference in absorption of the crisis generated a decline in the average for the whole period and, in many cases, growth rates in the poor states were higher than in the wealthier states.

Table 3. Average GDP growth rates of mexican states (2003-2013)

\begin{tabular}{lclclc}
\hline \multicolumn{1}{c}{ State } & GDP Growth & \multicolumn{1}{c}{ State } & GDP Growth & \multicolumn{1}{c}{ State } & GDP Growth \\
\hline Aguascalientes & $4.58 \%$ & Guerrero & $2.09 \%$ & Quintana Roo & $5.41 \%$ \\
Baja California & $2.29 \%$ & Hidalgo & $2.61 \%$ & San Luis Potosí & $3.77 \%$ \\
Baja California Sur & $5.89 \%$ & Jalisco & $3.07 \%$ & Sinaloa & $2.51 \%$ \\
Campeche & $-2.60 \%$ & México & $3.32 \%$ & Sonora & $4.69 \%$ \\
Coahuila de Zaragoza & & Michoacán de & & & \\
Colima & $3.03 \%$ & Ocampo & $2.13 \%$ & Tabasco & $4.42 \%$ \\
Chiapas & $2.92 \%$ & Morelos & $2.62 \%$ & Tamaulipas & $2.29 \%$ \\
Chihuahua & $1.29 \%$ & Nayarit & $3.62 \%$ & Tlaxcala & $1.79 \%$ \\
Distrito Federal & $3.31 \%$ & Nuevo León & $4.54 \%$ & de la Llave & $3.11 \%$ \\
Durango & $2.83 \%$ & Oaxaca & $2.01 \%$ & Yucatán & $3.34 \%$ \\
Guanajuato & $1.99 \%$ & Puebla & $3.07 \%$ & Zacatecas & $4.46 \%$ \\
\hline
\end{tabular}

Analysis of data for the years between 2003 and 2013 allows us to confirm this trend. We observe that the trends that contradict the theory only occur in the years immediately following the shocks; on the contrary, in non-crisis years growth rates behave as predicted by the theory in the sense that poorer states have lower rates than the richer. The maps below illustrate this point by comparing GDP growth rates by state in the years 2001 (when the economy was suffering the effects of the US recession) and 2003 (after the crisis). In the map, stronger colors indicate higher growth rates. 

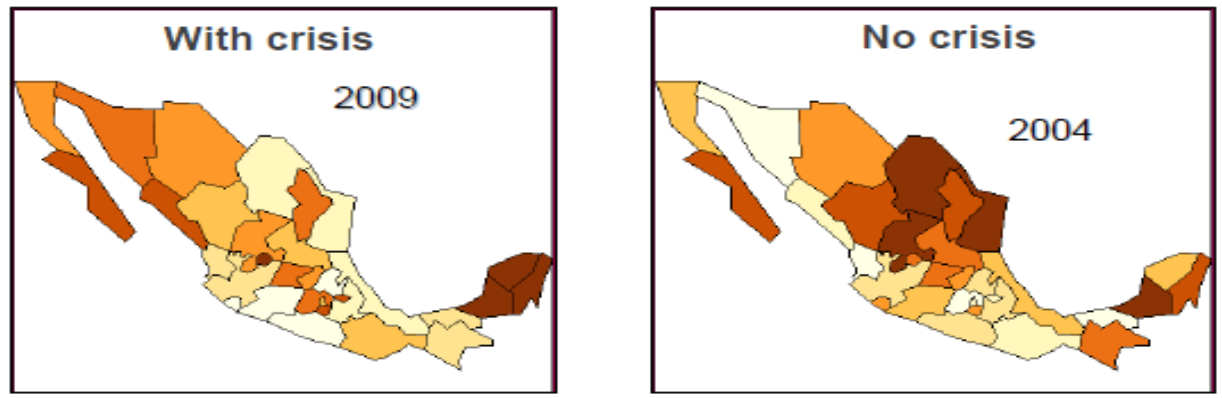

Map 5. State GDP growth rates in crisis and no crisis years

Figure 3 illustrates the relation between growth rates and income distribution in Mexico. On the left side, we see the scatter plot for the regression; states with the highest population in each interval are marked in yellow. On the right side, we include a box map that displays population distribution for each income range; darker colors indicate higher percentages.

When testing the relation between income levels and growth rates, we observe a markedly negative slope in the case of lower income ranges, implying that the states with the highest population with no income experienced lower growth rates, as shown in the graph and map for this income category. However, in the last two regressions we observe that this trend is reversed; the states with more population earning more than two times the minimum wage had higher growth rates in the following year.
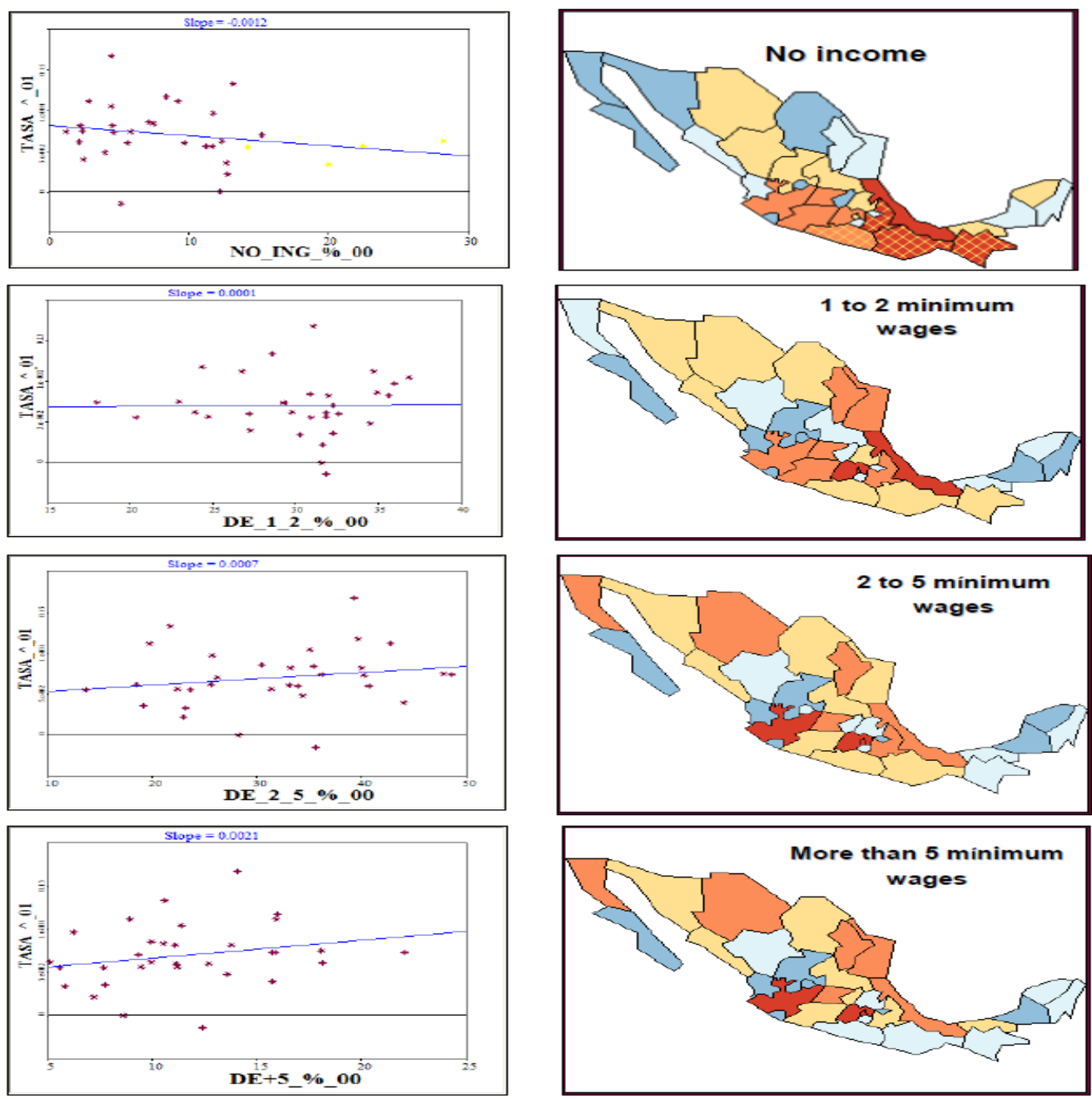

Figure 3 \& Map 6. Relationship between economic growth rates and income distribution in Mexico (2010) 


\section{Discussion}

Based on the theory proposed by De la Croix \& Doepke (2003) which suggests a negative causality between inequality and economic growth, this research analyzes the validity of this relationship for the case of Mexico. Using development, fertility, education and inequality indicators for the thirty-two Mexican states, together with a graphical modeling tool with polygon maps, we tested whether this theory holds for the Mexican economy.

We found that derived from the persistent inequalities between states, there are high differentials in fertility rates, schooling and mother's level of education between the poor and the rich states. These differences explain the uneven growth among Mexican states. Results show that, after controlling for the effects of external shocks, the richest states have higher growth rates than the poor.

Understanding the mechanisms through which inequality restrains economic growth allows us to identify which policies to apply in order to dismantle the vicious circle of wealth inequality. In this regard, the results suggest that redistributive policies are insufficient. Thus, we propose a comprehensive policy that promotes equal and universal access to education in order to boost economic growth. Finally, we put emphasis on the virtues of an educated society, which surpass productivity gains and the accumulation of human capital.

\section{References}

Ahituv, A., \& Moav, O. (2003). Fertility clubs and economic growth. In Eicher, T. S., \& Turnovsky, S. J. (Eds.), Inequality and Growth: Theory and Policy Implications (pp.61-87). Cambridge, London: MIT Press.

Banerjee, A. V., \& Duflo, E. (2000). A reassessment of the relationship between inequality and growth: A comment. MIT, mimeo.

Barro, R. J. (1999). Inequality, growth and investment. NBER Working Paper No. 7038. http://dx.doi.org/10.3386/w7038

Benabou, R. (1996). Inequality and growth. NBER Working Paper No. 5658. http://dx.doi.org/10.3386/w5658

Castelló-Climent, A., \& Doménech, R. (2006). Human capital, inequality, life expectancy and economic growth. Universidad de Valencia. Instituto de Economía Internacional. http://dx.doi.org/10.1111/j.1468-0297.2008.02136.x

Cortez, F. (2000). Procesos sociales y desigualdad económica en México. Siglo XXI Editores, Mexico.

De la Croix, D., \& Doepke, M. (2003). Inequality and growth: Why differential fertility matters. American Economic Review, 93(4), 1091-1113. http://dx.doi.org/10.1257/000282803769206214

Ferreira, F. (1999). Inequality and economic performance: A brief overview to theories of growth and distribution. Text for World Bank's web site on inequality, poverty, and socio-economic performance.

Forbes, K. J. (2000). A reassessment of the relationship between inequality and growth. American Economic Review, 90(4), 869-887. http://dx.doi.org/10.1257/aer.90.4.869

Galor, O., \& Zeira, J. (1993). Income distribution and macroeconomics. Review of Economic Studies, 60, 35-52.

Kaldor, N. (1956). Alternative theories of distribution. Review of Economic Studies, 23, 83-100.

Kuznets, S. (1955). Economic growth and income inequality. American Economic Review, 45(1), 1-28.

Li, H., \& Zou, H. F. (1998). Income inequality is not harmful for growth: Theory and evidence. Review of Development Economics, 2(3), 318-334. http://dx.doi.org/10.1111/1467-9361.00045

Lustig, N., \& Szekely, M. (1997). México: Evolución económica, pobreza y desigualdad. Banco Interamericano de Desarrollo.

Mankiw, G., Romer, D., \& Weil, D. (1992). A contribution to the empirics of economic growth. Quarterly Journal of Economics, 107, 407-437. http://dx.doi.org/10.2307/2118477

Perotti, R. (1996). Growth, income distribution and democracy: What the data say. Journal of Economic Growth, l(2), 149-187. http://dx.doi.org/10.1007/bf00138861

Perotti, R., \& Alesina, A. (1996). Income distribution, political instability, and investment. European Economic Review, 40(6), 1203-1228. http://dx.doi.org/10.1016/0014-2921(95)00030-5

Persson, T., \& Tabellini, G. (1994). Is inequality harmful for growth. American Economic Review, 84(3), 600-621.

Ray, D. (1999). Development Economics. Princeton: Princeton University Press. 
Robinson, S. (1976). A note on the U-hypothesis relating income inequality and economic development. American Economic Review, 66(3), 437-440.

Ros, J., \& Buillon, C. (2000). La liberalización de la balanza de pagos en México: efectos en el crecimiento, la desigualdad y la pobreza. In Ganuza, E. et al. (Eds.), Liberalización, desigualdad y pobreza; América latina y el Caribe en los 90 (pp.713-764). Buenos Aires: Eudeba - PNUD - CEPAL.

Stopler, W. F., \& Samuelson, P. A. (1941). Protection and real wages. Review of Economic Studies, 9(1), 58-73. http://dx.doi.org/10.2307/2967638

\section{Notes}

Note 1. Kuznets hypothesis was further developed by Robinson (1976)

Note 2. For instance, the fact that the richest country in the world, the USA, shares inequality indexes with countries like Guinea and even exceeds that of Pakistan.

Note 3. The most remarkable exception can be found in Veracruz, with a birth rate below the national average and second only to Distrito Federal. 